\title{
Oxidative depolymerization of kraft lignin to high-value aromatics using a homogeneous vanadium-copper catalyst
}

Walch, Florian; Abdelaziz, Omar; Meier, Sebastian; Bjelic, Sasa; Hulteberg, Christian; Riisager, Anders

Published in:

Catalysis Science and Technology

Link to article, DOI:

10.1039/D0CY02158J

Publication date:

2021

Document Version

Peer reviewed version

Link back to DTU Orbit

Citation (APA):

Walch, F., Abdelaziz, O., Meier, S., Bjelic, S., Hulteberg, C., \& Riisager, A. (2021). Oxidative depolymerization of kraft lignin to high-value aromatics using a homogeneous vanadium-copper catalyst. Catalysis Science and Technology, 11, 1843-1853. https://doi.org/10.1039/D0CY02158J

\section{General rights}

Copyright and moral rights for the publications made accessible in the public portal are retained by the authors and/or other copyright owners and it is a condition of accessing publications that users recognise and abide by the legal requirements associated with these rights.

- Users may download and print one copy of any publication from the public portal for the purpose of private study or research.

- You may not further distribute the material or use it for any profit-making activity or commercial gain

- You may freely distribute the URL identifying the publication in the public portal 
Received 00th January 20xx, Accepted 00th January 20xx DOI: $10.1039 / \times 0 \times x 00000 x$

\title{
Oxidative depolymerization of kraft lignin to high-value aromatics using a homogeneous vanadium-copper catalyst ${ }^{\dagger}$
}

\author{
Florian Walch, ${ }^{a}$ Omar Y. Abdelaziz, ${ }^{b}$ Sebastian Meier, ${ }^{c}$ Saša Bjelić, ${ }^{d}$ Christian P. Hulteberg ${ }^{b}$ and \\ Anders Riisager* ${ }^{\mathrm{a}}$
}

\begin{abstract}
Lignin, the world's most abundant biopolymer with high aromaticity, has huge potential as a renewable feedstock replacing petroleum for the production of chemicals, fuels and functional materials. Enhanced utilization of lignin would improve the economic viability of existing pulp and paper mills, as well as lignocellulosic biorefineries, where lignin is highly available, but mostly incinerated for energy recovery. Catalysis could be of crucial importance to improve current depolymerization strategies, and hence contribute to the more sustainable and responsible use of terrestrial resources. In the present study, the impact of different homogeneous transition-metal catalysts on the oxidative depolymerization of a technical softwood kraft lignin was examined. The depolymerization reactions were carried out using molecular oxygen under rather mild operating conditions and the produced aromatic monomers included, among others, vanillin, vanillic acid and acetovanillone. The best performing system incorporated a $\mathrm{VO}(\mathrm{acac})_{2}-\mathrm{Cu}(\mathrm{OAc})_{2}$-catalyst $(\mathrm{V}$ - $\mathrm{Cu})$, yielding $3.5 \%$ vanillin and $2.8 \%$ vanillic acid, with a bio-oil yield of approximately $50 \%$ and a total increase in aromatic monomers of $27 \%$, on a weight basis. Moreover, a favorable combined effect between $\mathrm{VO}(\mathrm{acac})_{2}$ and $\mathrm{Cu}(\mathrm{OAc})_{2}$ was suggested by $\mathrm{NMR}$ spectroscopy. UHPLC-HRMS and corresponding statistical analysis revealed a more than 30-fold increase in two aromatic molecules with an oxoacetic functionality and oxalic acid as well as a focusing effect on selected molecules, when employing the V-Cu catalyst. The findings of this study indicate that the V-Cu catalyst system is promising for the efficient refining of technical lignin into value-added aromatic chemicals. However, catalyst recycling and reuse must be demonstrated for successful implementation under industrial conditions.
\end{abstract}

\section{Introduction}

The valorization of biomass represents a promising and sustainable alternative for the production of platform chemicals, fine chemicals, functional materials and fuels, compared to petroleum-based processes. ${ }^{1-4}$ Lignin, the most abundant non-carbohydrate polymer in biomass, is of particular interest, as it comprises the world's largest renewable source of aromatic compounds. Lignin makes up $10-40 \%$ of the dry weight of woody biomass and grasses. ${ }^{4-7}$ The biopolymer is composed of three aromatic moieties, namely $p$-hydroxyphenyl $(\mathrm{H})$, guaiacyl $(\mathrm{G})$, and syringyl $(\mathrm{S})$ units (Fig. 1). These units are cross-linked via different carboncarbon and/or carbon-oxygen bonds, of which the $\beta-0-4^{\prime}$ and 5-5' bonds appear most often, with respective abundances of

\footnotetext{
Centre for Catalysis and Sustainable Chemistry, Department of Chemistry, Technical University of Denmark, Kemitorvet 207, 2800 Kgs. Lyngby, Denmark. E-mail: ar@kemi.dtu.dk

b. Department of Chemical Engineering, Lund University, Naturvetarvägen 14, 22100 Lund, Sweden

Department of Chemistry, Technical University of Denmark, Kemitorvet 207, 2800 Kgs. Lyngby, Denmark

d. Laboratory for Bioenergy and Catalysis, Paul Scherrer Institute, Forschungsstrasse 111, 5232 Villigen, Switzerland

† Electronic Supplementary Information (ESI) available. See

DOI: $10.1039 / x 0 x x 00000 x$
}

$45-50 \%$ and $18-25 \%$ in softwood. However, the fraction of $\mathrm{H}-$, G- and S-units and the proportion of linkages varies considerably between hardwood, softwood and grasses. ${ }^{8-10}$ Moreover, the composition of lignin is dependent on the extraction process used to separate it from cellulose and hemicellulose, ${ }^{11-15}$ where the fraction of C-C bonds is increasing in technical lignins as compared to native lignins due to condensation reactions. ${ }^{16,17}$ Despite the heterogeneity of lignin causing several difficulties, its unique chemical structure and the high bioavailability of this renewable, nonedible feedstock offers a huge potential towards its industrial implementation. ${ }^{18}$ However, in pulp and paper mills as well as in lignocellulosic biorefineries, where lignin is generated in large quantities, the focus currently lies on the valorization of carbohydrates. In contrast, lignin is mainly utilized for heat and power generation. ${ }^{19,20}$

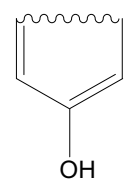

p-Hydroxyphenyl $(\mathrm{H})$

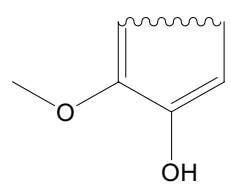

Guaiacyl (G)

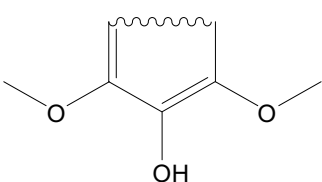

Syringyl (S)
Fig. 1 Chemical structure of the three aromatic moieties of lignin, $p$-hydroxyphenyl $(H)$, guaiacyl (G), and syringyl (S) residues. 
To fully exploit the potential of lignin and to make it more attractive to the pulp and paper industry and lignocellulosic biorefineries, catalysis could play a key role in depolymerizing lignin into value-added aromatic monomers. ${ }^{21}$ In order to keep the native functional groups of the aromatic moieties and add functionality, oxidative depolymerization strategies seem most promising. ${ }^{1,4,22,23}$ Typical depolymerization products are platform or fine chemicals, such as phenolic aldehydes and acids, fractionated into a viscous bio-oil by solvent extraction. ${ }^{4,24,25} \mathrm{~A}$ wide range of homogeneous and heterogeneous catalysts has previously been evaluated, including metal salts, metal oxides, coordination complexes, composites of metal oxides, polyoxometalates, organometallics, metal-organic frameworks, organocatalysts and enzymes. , $12,21,26-28$ However, the nature of the obtained compounds is dependent on the used lignin (or lignin model compound), reaction conditions and media or oxidant. Therefore, it is rather difficult to effectively compare the performance of the aforementioned catalysts.

Among homogeneous catalysts, Cu-, $\mathrm{Mn}-, \mathrm{Co}_{-}, \mathrm{Fe}-$ and $\mathrm{V}-$ based catalysts showed promising catalytic activity in depolymerizing lignin into valuable aromatic compounds. ${ }^{4,19,29-}$ ${ }^{32}$ Copper and vanadium catalysts have shown to selectively cleave the $\mathrm{C}-\mathrm{C}$ bonds in the oxidative depolymerization reactions. ${ }^{33-35}$ Reaction mechanisms for vanadium-catalyzed oxidative cleavages have been proposed. ${ }^{35-37}$ Yet, most of the studies have dealt with lignin model compounds or native lignin, whereas investigations on technical lignin are rather seldom. ${ }^{38}$ As model compounds often represent one specific type of lignin linkage, ${ }^{4,23}$ studies on real complex feedstocks, including technical lignin, should be preferred to gain insights into representative product functionalities.

In the present study, we address the gap in studies of technical lignin conversion by investigating the oxidative depolymerization of a technical LignoBoost (LB) kraft lignin from softwood. The objective was to produce high-value aromatic monomers and high-quality bio-oil under rather mild conditions, using oxygen gas as the environmentally benign primary oxidant and an alkaline water solution as the solvent. Different homogeneous catalysts were tested, and their performance was assessed. A potential combined effect on the cleavage of different lignin linkages by a V-Cu based catalyst was found, and the system was further optimized. Compared to previous studies dealing with a related catalytic system, ${ }^{30,31}$ this study rather focused on the identification and quantification of the major reaction products that could be generated from a real industrial lignin stream than on gaining mechanistic insights from conversion of model compounds. In addition, the reaction medium used in the present study was a $\mathrm{NaOH}$ aqueous solution, whereas in the related studies, organic solvents, such as pyridine or toluene, had been used. The possibility of using the $\mathrm{NaOH}$ available in a kraft pulp mill as an active cooking chemical renders the proposed approach attractive from a process integration perspective. ${ }^{39}$

\section{Experimental}

\section{Chemicals and materials}

$\mathrm{VO}(\mathrm{acac})_{2}(95 \%), \mathrm{Cu}(\mathrm{OAc})_{2} \cdot \mathrm{H}_{2} \mathrm{O}$, vanillin $(99 \%)$, vanillic acid (97\%), 4-hydroxybenzaldehyde (98\%), acetovanillone (98\%), $\mathrm{HCl}$ (aq. solution, $37 \mathrm{wt} \%), \mathrm{NaOH}(98 \%)$ and DMSO-d 6 (99.9\%) were purchased from Sigma-Aldrich. Ethyl acetate (EtOAc, $\mathrm{HPLC}$ grade), acetone (HPLC grade), $\mathrm{Na}_{2} \mathrm{SO}_{4}$ anhydrous (99.8\%) and qualitative filter paper $413(55 \mathrm{~mm})$ were purchased from VWR International. 4-Hydroxybenzoic acid (99\%) was purchased from Fluka Chemical, and $\mathrm{Mn}(\mathrm{OAc})_{2}$ (98\%) was purchased from Merck. Oxygen gas (99.5\%) was purchased from Air Liquide Denmark. LB softwood kraft lignin was obtained as a dry powder from the LignoBoost demonstration plant in Bäckhammar, Sweden. LB is characterized by its rather low ash and carbohydrate contents and a sulfur content usually in the range of $1-3 \% .^{40}$ Deionized water was used throughout all experiments. All materials were used as received.

\section{Depolymerization reactions}

In a typical experiment, an autoclave (Parr Instrument Company, $300 \mathrm{~mL}$, equipped with a Parr 4848 reactor controller and a Teflon insert) was loaded with $60 \mathrm{~mL}$ of an aqueous $25 \mathrm{~g} / \mathrm{L}$ lignin in $2 \mathrm{M} \mathrm{NaOH}$ solution and the respective amount of catalyst. The reactor was sealed and purged with oxygen gas three times and pressurized to the desired $\mathrm{O}_{2}$ partial pressure. Stirring $(700 \mathrm{rpm})$ was applied and the reactor was heated up to the desired temperature (45 $\mathrm{min}$ to reach $\left.150{ }^{\circ} \mathrm{C}\right)$. Reaction time was considered to start after the respective reaction temperature was reached.

After the desired reaction time was reached, the autoclave

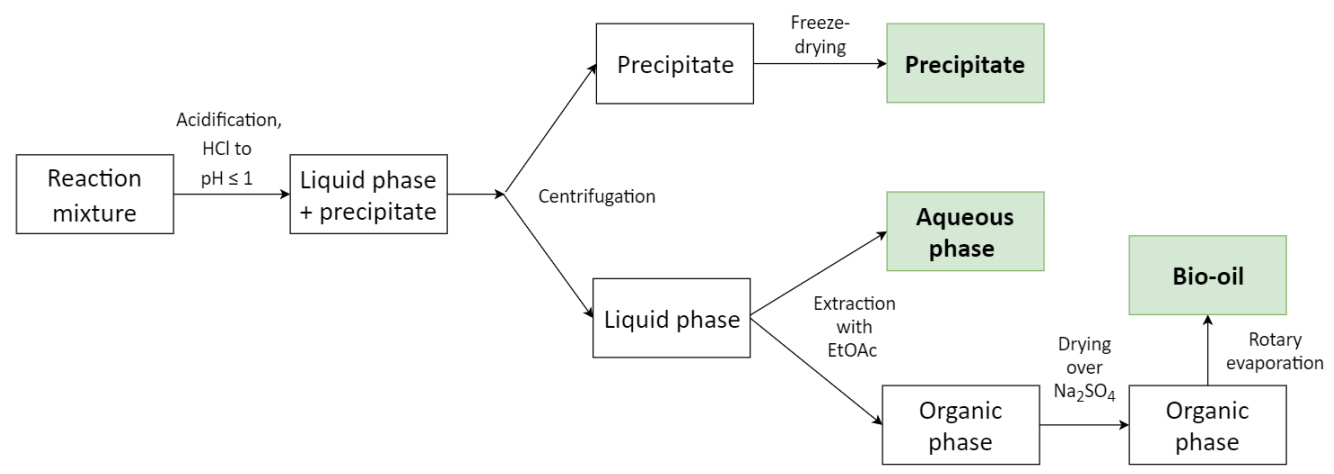

Fig. 2 Schematic depiction of the workup procedure upon oxidative depolymerization of LB kraft lignin. 
was quenched in an ice bath to cool it down to room temperature, which typically took $30 \mathrm{~min}$. The reactor was then opened, the liquid product mixture was collected and was stored in a freezer $\left(-20{ }^{\circ} \mathrm{C}\right)$, in order to inhibit possible condensation reactions. Solid residues remaining in the reaction chamber were rinsed with water and were then stored at $-20^{\circ} \mathrm{C}$ until further usage.

\section{Workup procedure of reaction products}

An aliquot of $20 \mathrm{~mL}$ of the product mixture $(\mathrm{pH}>13)$ was acidified with aqueous $\mathrm{HCl}$ to $\mathrm{pH} \leq 1$, leading to precipitation of heavy lignin fragments. In order to separate the two phases, the resulting mixture was centrifuged $(3900 \mathrm{rpm})$ for $20 \mathrm{~min}$. After centrifugation, the liquid phase was transferred to a separation funnel. Residual solvent in the remaining solid fraction (precipitate) was evaporated in a freeze-dryer (Scanvac Coolsafe 110-4 Pro) until dryness, the solid was balanced and stored in the fridge $\left(4{ }^{\circ} \mathrm{C}\right)$ until further analysis. The liquid phase was extracted with EtOAc three times $(2 \times$ $15 \mathrm{~mL}, 1 \times 30 \mathrm{~mL}$ ) and the remaining aqueous fraction was collected and stored in the fridge $\left(4^{\circ} \mathrm{C}\right)$ until further analysis. The combined organic phases were dried over anhydrous $\mathrm{Na}_{2} \mathrm{SO}_{4}$. EtOAc was evaporated with a rotary evaporator (IKA RV 10) at $40{ }^{\circ} \mathrm{C}$ and approximately 210 mbar to yield a brownish bio-oil. The yield of bio-oil was calculated gravimetrically based on the initial lignin weight fed into the reactor, as shown in eqn (1).

Bio-oil yield $[w t \%]=\frac{m(\text { Bio-oil }) \times 3}{m(\text { Lignin })} \times 100$

The resulting dry bio-oil was then analyzed. Typically, about $50 \mathrm{mg}$ of bio-oil were used instantaneously for the quantification of monomers. The remaining bio-oil was dissolved in ca. $5 \mathrm{~mL}$ acetone, sealed and stored in the fridge $\left(4{ }^{\circ} \mathrm{C}\right)$ until further use.

A schematic flowchart of the workup procedure is shown in Fig. 2. Selected reactions were performed in duplicate or triplicate, and eqn (2) was used to calculate the yields of monomers.

Monomer yield $[w t \%]=\frac{m(\text { Monomer })_{N M R}}{m(\text { Bio-oil })_{N M R}} \times$ Bio-oil yield

\section{Size exclusion chromatography (SEC)}

Size exclusion chromatography (SEC) was used to determine the molecular weight distribution (MWD), the weight-average molecular weight $\left(\mathrm{M}_{\mathrm{w}}\right)$, and the number-average molecular weight $\left(M_{n}\right)$ of the unreacted LB lignin and the oxidatively depolymerized lignin products. The SEC system consisted of a Waters Alliance 2695 high-performance liquid chromatography (HPLC) setup (Milford, MA, USA) with a Waters 2487 UV detector. The system was controlled and peak evaluations were managed using Waters Empower 3 chromatography data software. A Superdex 200 Increase 10/300 GL column (GE Healthcare Bio-Sciences $A B$, Uppsala, Sweden) was used to ensure high resolution over a large range of molecular weights. Calibration was carried out using different sodium polystyrene sulfonate standards from Polymer Standards Service $\mathrm{GmbH}$ (Mainz, Germany). Each sample was diluted with $0.1 \mathrm{M} \mathrm{NaOH}$ to a concentration of $0.5 \mathrm{~g} / \mathrm{L}$ and filtered $(0.2 \mu \mathrm{m})$ to remove any suspended matter. The volume of filtered solution injected into the SEC system was $10 \mu \mathrm{L}$ and elution was performed for 60 min using an aqueous solution containing $0.1 \mathrm{M} \mathrm{NaOH}$.

\section{Nuclear magnetic resonance (NMR)}

Samples for NMR analysis were prepared by redissolving $50 \mathrm{mg}$ bio-oil in $550 \mu \mathrm{L}$ DMSO- $\mathrm{d}_{6}$ and transferring the samples to a $5 \mathrm{~mm} \mathrm{NMR}$ tube. All spectra were acquired at $25^{\circ} \mathrm{C}$ using an $800 \mathrm{MHz}$ Bruker Avance III instrument equipped with a TCI cryoprobe and a SampleJet sample changer. One-dimensional ${ }^{13} \mathrm{C}$ spectra were acquired with $30 \mathrm{~s}$ of recycle delay, sampling $64 \mathrm{k}$ complex data points during $1.36 \mathrm{~s}$ of acquisition time. ${ }^{1} \mathrm{H}-$ ${ }^{13} \mathrm{C}$ heteronuclear single quantum coherence (HSQC) spectra with $140 \mathrm{ppm}$ spectral width in the ${ }^{13} \mathrm{C}$ dimension were acquired as data matrices of $1024\left({ }^{1} \mathrm{H}\right) \times 256\left({ }^{13} \mathrm{C}\right)$ complex data points to probe the linkage region and the chemical composition of the substrate. Reaction products were identified and quantified as detailed below by acquisition of ${ }^{1} \mathrm{H}-{ }^{13} \mathrm{C}$ HSQC spectra of $60 \mathrm{ppm}$ spectral width centered in the aromatic spectral region, sampling $2048\left({ }^{1} \mathrm{H}\right) \times 512\left({ }^{13} \mathrm{C}\right)$ complex data points with 2 accumulations per increment, a recycle delay of 1.2 seconds and non-uniform sampling of $50 \%$ of the data points in the indirect dimension. All NMR spectra were processed with ample zero filling and baseline corrections in all dimensions using Bruker Topspin $3.5 \mathrm{pl} 7$ and were integrated into the same software.

\section{Quantitative ${ }^{1} \mathrm{H}-{ }^{13} \mathrm{C}$ NMR}

Conventional one-dimensional NMR spectroscopy is inherently quantitative, if precautions are taken to ensure that full recovery occurs between accumulated transients. Such a quantitative NMR (qNMR) approach is not always viable for quantification in complex reaction material, however, it has been concluded in previous studies that two-dimensional NMR-based quantifications can be superior to ${ }^{1} \mathrm{H}$ NMR-based quantifications in complex mixtures, specifically when using highly-resolved ${ }^{1} \mathrm{H}-{ }^{13} \mathrm{C}$ HSQC spectra. ${ }^{41} \mathrm{HSQC}$ spectra are not inherently quantitative due to relaxation during transfer periods and as signal amplitude modulates with scalar coupling between ${ }^{1} \mathrm{H}$ and ${ }^{13} \mathrm{C}$. These problems can be circumvented, when using the ${ }^{1} \mathrm{H}-{ }^{13} \mathrm{C}$ HSQC spectrum as a detection modality, while calibrating the response through gravimetrically defined reference compounds.

Standard solutions were prepared by dissolving vanillin, vanillic acid, 4-hydroxybenzaldehyde, acetovanillone and 4hydroxybenzoic acid in DMSO- $\mathrm{d}_{6}$ (about $5 \mathrm{mg}$ in $550 \mu \mathrm{L}$ ), and transferred to a $5 \mathrm{~mm}$ NMR tube. Standards were used both for identification and quantification with high-resolution ${ }^{1} \mathrm{H}-$ ${ }^{13} \mathrm{C}$ spectra. Reference samples were gravimetrically prepared in DMSO- $_{6}$ and analyzed under identical conditions for 
identification and quantification. The estimated deviation resulting from the signal-to-noise ratio in the NMR determinations was $\pm 0.01 \mathrm{wt} \%$. Spectra used in the identification and quantification of select compounds in the post-reaction material are presented in Fig. S2, ESIt.

\section{Ultra high-performance liquid chromatography (UHPLC)-high-} resolution mass spectrometry (HRMS)

For UHPLC-HRMS analysis, $1 \mu \mathrm{L}$ of the 100 times diluted sample with water was injected into a liquid chromatographymass spectrometry (LC-MS) system. The time-resolved separation of the analytes was performed in a Dionex Ultimate 3000 Series RS system (Thermo Scientific, Basel, Switzerland) including a pump, a column compartment and an autosampler. The column and pre-column were Thermo Scientific Accucore RP-MS $(150 \mathrm{~mm} \times 2.1 \mathrm{~mm}$, particle size $2.6 \mu \mathrm{m})$. The following program with mobile phase A (1 vol.\% $\mathrm{MeOH}, 1$ vol.\% $\mathrm{CH}_{3} \mathrm{CN}$ and 0.2 vol. $\% \mathrm{HCOOH}$ in high purity water) and mobile phase B (100 vol.\% $\mathrm{MeOH})$ was applied: $1 \%$ B (0-1min) 1 to $99 \%$ B (1-6 $\mathrm{min}), 99 \%$ B $(6-8 \mathrm{~min})$, followed by equilibration step and 99 to $1 \%$ B $(8-8.2 \mathrm{~min}), 1 \% \mathrm{~B}(8.2-10$ $\mathrm{min}$ ). The flow was set to $0.7 \mathrm{~mL} / \mathrm{min}$, while the temperature of the column was kept constant at $50{ }^{\circ} \mathrm{C}$. Heated electrospray ionization (ESI, $3.5 \mathrm{kV}$ spray voltage) in positive and negative mode was used for the ionization of the analytes.

Data acquisition was performed using a Thermo Scientific Q Exactive hybrid quadrupole-orbitrap mass spectrometer controlled by Xcalibur 4.1 software. Mass spectra were acquired in full scan mode with an isolation window of $1 \mathrm{~m} / \mathrm{z}$ from $50-750 \mathrm{~m} / \mathrm{z}$. The resolution was 70000 . The raw mass spectral data files were collected in triplicate. The UHPLC HRMS data were imported into Compound Discoverer 3.1 software (Thermo Scientific, Switzerland) and processed with standard settings except for mass tolerance (set to $2.5 \mathrm{ppm}$ ). Chromatographic peaks detected in one of the input files, but missing in others, were checked by the "Fill Gaps" option. The composition (of a general formula $\mathrm{C}_{\mathrm{c}} \mathrm{H}_{\mathrm{h}} \mathrm{O}_{\mathrm{o}}$ ) was predicted based on exact mass and isotopic patterns and evaluated against MS/MS spectra. The cutoff value for the area was set to $5 \times 10^{6}$. The identity of the compounds was determined with mzCloud, where possible. Only features yielding formulas present in ChemSpider were used. Tentative identification was performed using the FISh score algorithm (Fig. S1, ESI†).

The statistical significance of perturbations between different runs was assessed using volcano plots, which plot $\log _{2}$ of the fold-change on the $x$-axis versus significance $\left(-\log _{10}\right.$ of the p-value from a post-hoc ANOVA analysis) on the $y$-axis. The fold change was calculated as the ratio of the area under the peak from corresponding runs. Statistically relevant changes in the composition can be found where the following conditions are met: $p$-value $<0.05$ as well as $\log _{2}<-2$ or $\log _{2}>$ 2 for significantly downregulated and significantly upregulated species, respectively. In the absence of strict rules, a value of $\log _{2}=2$ as cutoff value is widely accepted. ${ }^{42,43}$

\section{Results and discussion}

\section{Screening of homogeneous catalysts}

A screening of homogeneous transition-metal based catalysts was performed to evaluate their ability to catalyze the oxidative depolymerization of lignin to monomeric aromatic compounds. Five different catalytic systems were tested. The catalysts were primarily assessed based on their selectivity towards vanillin and vanillic acid. The reaction conditions were kept constant throughout the screening and quantification of the monomeric aromatic products was carried out by ${ }^{1} \mathrm{H}-{ }^{13} \mathrm{C}$ HSQC NMR spectroscopy. Exemplary spectra used in the identification and quantification of select compounds in the post-reaction material are presented in Fig. S2, ESIt. The concentration of $\mathrm{NaOH}(2 \mathrm{M})$ was chosen to maintain $\mathrm{pH}>13$ for the entire reaction. Maintaining high $\mathrm{pH}$ is important as acidic products of depolymerization might lower the $\mathrm{pH}$, reportedly influencing the degradation of produced vanillin due to oxidation. ${ }^{44}$ However, the usage of even higher $\mathrm{NaOH}$ concentrations was reported to lead to operational problems. $^{19}$

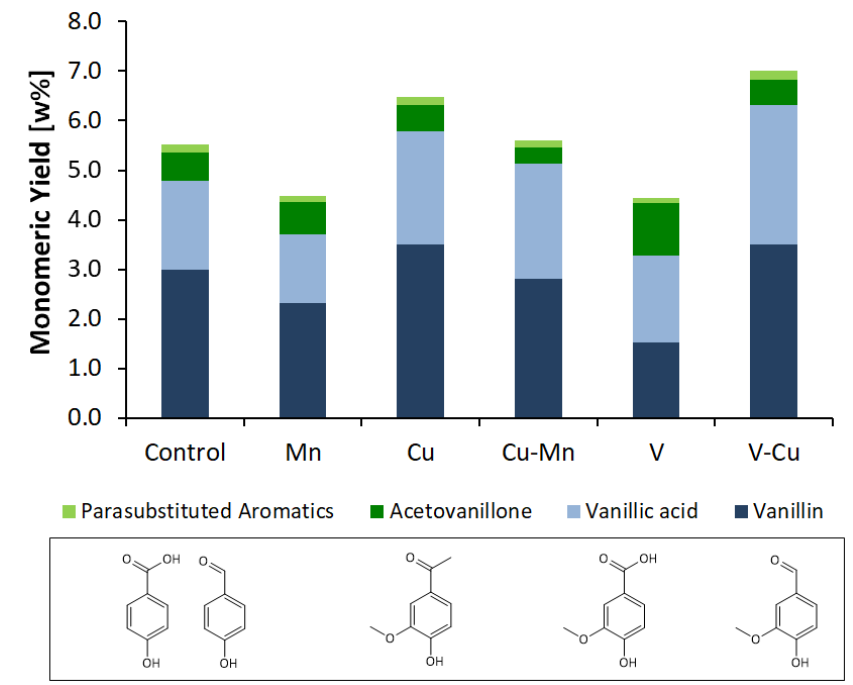

Fig. 3 Yields of the identified monomeric aromatic compounds and their respective chemical structures during the oxidative depolymerization. "Parasubstituted Aromatics" describes a combination of the small yields of 4-hydroxybenzoic acid and 4hydroxybenzaldehyde. Reaction conditions: $150{ }^{\circ} \mathrm{C}, 10 \mathrm{~min}, 5$ bar initial $\mathrm{O}_{2}, 60 \mathrm{~mL}$ of 25 $\mathrm{g} / \mathrm{L}$ lignin in $2 \mathrm{M} \mathrm{NaOH}$. $\mathrm{Mn}: \mathrm{Mn}(\mathrm{OAc})_{2}, \mathrm{Cu}: \mathrm{Cu}(\mathrm{OAc})_{2}, \mathrm{~V}$ : $\mathrm{VO}(\mathrm{acac})_{2}$. Monomer yields given in mass of respective monomer per mass of initial lignin. The control reaction was performed in triplicate, the $\mathrm{V}$-Cu-catalyzed reaction in duplicate, and the respective average values are given. Amounts and ratios of the respective catalysts are given in Table S1, ESIt.

In terms of selectivity towards vanillin, the $\mathrm{Cu}(\mathrm{OAc})_{2}$ and $\mathrm{VO}(\mathrm{acac})_{2}-\mathrm{Cu}(\mathrm{OAc})_{2} \quad(\mathrm{~V}-\mathrm{Cu})$ catalyst systems gave increased vanillin yields of about $3.5 \%$, compared to the control reaction (no added catalyst) and the other tested catalysts, where yields in the range of $1.5-3 \%$ were obtained (Fig. 3). Comparing these two systems, the yields obtained for acetovanillone, 4hydroxybenzoic acid and 4-hydroxybenzaldehyde were rather similar. However, the V-Cu catalyst provided a higher yield in vanillic acid than $\mathrm{Cu}(\mathrm{OAc})_{2}$ catalyst alone. Hence, either $\mathrm{VO}(\mathrm{acac})_{2}$ seemed to inhibit the formation of vanillin or, more likely, promote its further oxidation to vanillic acid, as the 
obtained yield in vanillin was considerably lower than for the control reaction. Thus, for the combined V-Cu catalyst system, a combined effect between the components was observed, as the selectivity towards vanillin was enhanced by the catalysis with $\mathrm{VO}(\mathrm{acac})_{2}$ and the yield in vanillic acid increased compared to catalysis by $\mathrm{Cu}(\mathrm{OAc})_{2}$.

Due to the aforementioned differences in the yields of vanillin and vanillic acid, the total amount of the five quantified aromatic monomers (vanillin, vanillic acid, acetovanillone, 4-hydroxybenzoic acid and 4-hydroxybenzaldehyde) increased up to $7.0 \%$ upon $\mathrm{V}$-Cu catalysis, compared to $5.5 \%$ in the control reaction and $6.5 \%$ in the Cu-catalyzed reaction. This corresponds to an improvement in the total monomer yield of $27 \%$ and $18 \%$ comparing the $\mathrm{V}-\mathrm{Cu}$ - and the Cu-catalyzed reactions to the control reaction, respectively. Conversely, the catalyst composed of $\mathrm{Cu}(\mathrm{OAc})_{2}$ and $\mathrm{Mn}(\mathrm{OAC})_{2}$ did not show similar combined effects, as the yield of vanillin $(2.8 \%)$ ranged between the yields observed when using the individual catalysts ( $3.5 \%$ for $\mathrm{Cu}(\mathrm{OAc})_{2}$ and $2.3 \%$ for $\mathrm{Mn}(\mathrm{OAc})_{2}$ ).

The combined effect of $\mathrm{V}$-Cu catalysis is in line with previous observations on lignin model compounds ${ }^{30,31}$ and lignin. ${ }^{31}$ The reaction mechanisms most likely proceed via a combination of $\mathrm{C}-\mathrm{C}$ and $\mathrm{C}-\mathrm{O}$ bond cleavages. Nonetheless, selective $\mathrm{C}-\mathrm{C}$ bond cleavages have been shown employing $\mathrm{Cu}$ ${ }^{34}$ or V-catalysis. ${ }^{33}$ The selectivity between $\mathrm{C}-\mathrm{C}$ or $\mathrm{C}-\mathrm{O}$ bond cleavage was also shown to be dependent on the nature of the employed V-catalyst. ${ }^{35}$ However, to elucidate specific cleavages of interunit linkages and reaction mechanisms, studies on lignin model compounds seem more appropriate. Lignin model compounds resemble common linkages found in the lignin polymer in a simpler molecule, aiming to facilitate analysis of the reaction pathways. ${ }^{4,45} \mathrm{~A}$ recent study also showed the stability of the obtained aromatic products (e.g. vanillin) under alkaline oxidative depolymerization conditions to be crucial. ${ }^{46}$ Overall, the reaction pathways are dependent on several parameters, such as the chemical nature of $\mathrm{V}$ - and Cu-catalysts, reaction conditions and solvent, and require further research.

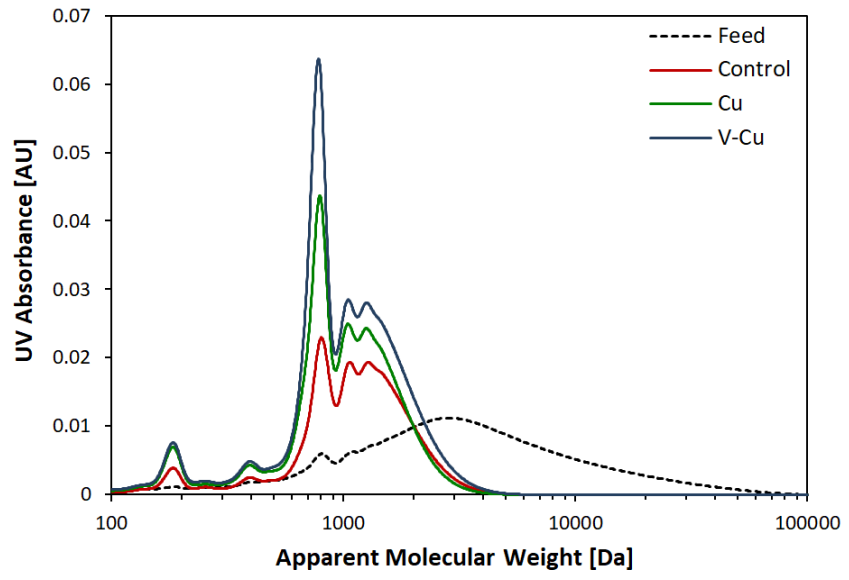

Fig. 4 Molecular weight distributions of the unprocessed lignin feed, the control and selected catalyzed samples after oxidative depolymerization. Reaction conditions: 150 ${ }^{\circ} \mathrm{C}, 10 \mathrm{~min}, 5$ bar initial $\mathrm{O}_{2}, 60 \mathrm{~mL}$ of $25 \mathrm{~g} / \mathrm{L}$ lignin in $2 \mathrm{M} \mathrm{NaOH}$. $\mathrm{Cu}$ : $\mathrm{Cu}(\mathrm{OAc})_{2}, \mathrm{~V}$ : $\mathrm{VO}(\mathrm{acac})_{2}$. Amounts and ratios of respective catalysts are given in Table S2, ESI†.
SEC was carried out in order to follow the degree of depolymerization and molecular weight distributions (MWDs) for the respective catalytic depolymerization reactions. As indicated in Fig. 4, depolymerization was clearly successful for the two catalyzed reactions using $\mathrm{Cu}(\mathrm{OAc})_{2}$ and $\mathrm{V}-\mathrm{Cu}$ catalyst and for the control reaction. This observation is also reflected by a decrease in the MWD (Table S2, ESIt). The $\mathrm{M}_{\mathrm{w}}$ decreased from a very broad distribution of $5980 \mathrm{Da}$ (unprocessed lignin feed) to $1135 \mathrm{Da}(\mathrm{V}-\mathrm{Cu})$, and $\mathrm{M}_{\mathrm{n}}$ analogously decreased from $1668 \mathrm{Da}$ to $790 \mathrm{Da}$. In consequence, a narrower distribution of molecular weight was achieved, as confirmed by the polydispersity index (PDI), which decreased from 3.58 for the unprocessed lignin to $\leq 1.44$ for oxidative depolymerized samples.

The obtained values in $M_{w}$ and $M_{n}$ were slightly lower for the catalyzed depolymerization reactions than for the control reaction. However, the signal at the peak ranging between 160 and $200 \mathrm{Da}$ was higher for the two catalyzed reactions than for the control reaction (Fig. 4). This observation is consistent with higher amounts of the aromatic monomers vanillin, vanillic acid and acetovanillone produced within the catalyzed reactions, as the aromatic monomers should be observed in this region. Although the performance of $\mathrm{V}-\mathrm{Cu}$ and $\mathrm{Cu}(\mathrm{OAc})_{2}$ in terms of producing monomeric and dimeric products was rather similar according to SEC, a higher concentration of oligomeric products was observed in the case of $\mathrm{V}-\mathrm{Cu}$, which is indicated by higher absorbance in the region of 700-800 Da.

\section{NMR analysis}

${ }^{1} \mathrm{H}-{ }^{13} \mathrm{C}$ HSQC NMR spectroscopy was performed on the LB substrate and on the bio-oils obtained from after the catalytic reactions (Fig. 5). The main linkages identified in the feedstock are displayed in Fig. 6 , deriving from $\beta$-aryl-ether ( $\beta-O-4)(A)$, phenylcoumaran $(\beta-5)(B)$ and resinol $(\beta-\beta)(C)$ units. Regarding the aromatic region, the most prominent peaks were obtained from guaiacyl $(G)$ units, which is characteristic for softwood lignin. Guaiacyl units are of major importance for the formation of vanillin, vanillic acid and acetovanillone. Additionally, $p$-hydroxyphenyl $(\mathrm{H})$ units were detected, albeit in significantly lower amounts than guaiacyl units.

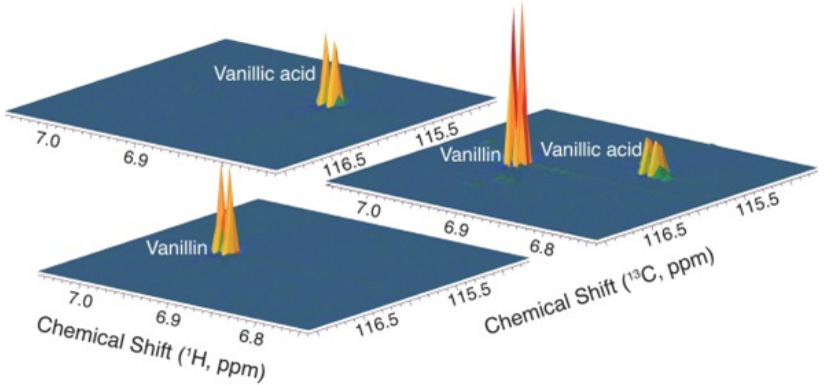

Fig. 5 Graphical representation of selected signals used in ${ }^{1} \mathrm{H}-{ }^{13} \mathrm{C}$ HSQC NMR for identification and quantification (using the response for gravimetrically defined reference amounts). Front: vanillin standard, back: vanillic acid standard, right: products of bio-oil of $\mathrm{V}$-Cu catalyzed reaction. Reaction conditions: $150{ }^{\circ} \mathrm{C}, 10 \mathrm{~min}, 5$ bar initial $\mathrm{O}_{2}, 60 \mathrm{~mL}$ of $25 \mathrm{~g} / \mathrm{L}$ lignin in $2 \mathrm{M} \mathrm{NaOH}, 1.4 \mathrm{mmol} \mathrm{VO}(\mathrm{acac})_{2}-\mathrm{Cu}(\mathrm{OAc})_{2}(\mathrm{~V}: \mathrm{Cu}$ ratio $=0.75$ ). 


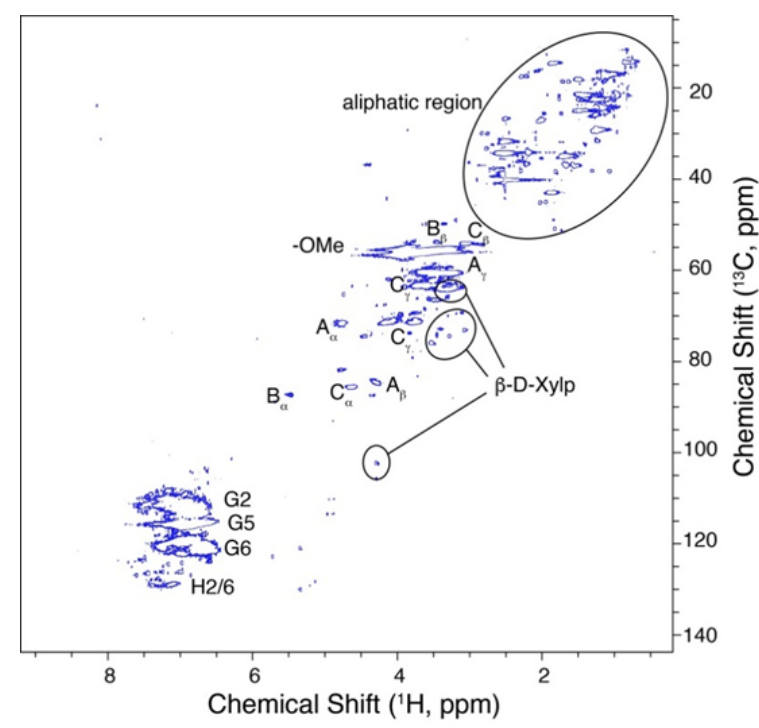

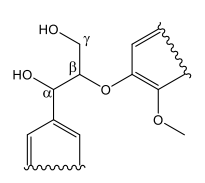

A

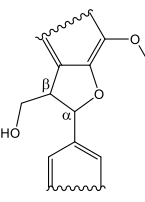

B

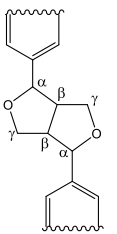

C

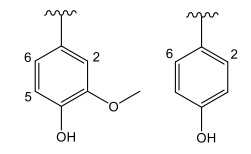

H
Fig. $6{ }^{1} \mathrm{H}-{ }^{13} \mathrm{C}$ HSQC spectrum of the LB substrate (top) and chemical structures of the respective units (bottom). A: $\beta$-aryl-ether ( $\beta-0-4), B$ : phenylcoumaran ( $\beta-5)$, resinol ( $\beta$ - $\beta$ ), G: guaiacyl, $\mathrm{H}$ : $p$-hydroxyphenyl, $\beta$-D-Xylp: $\beta$-D-xylopyranoside.

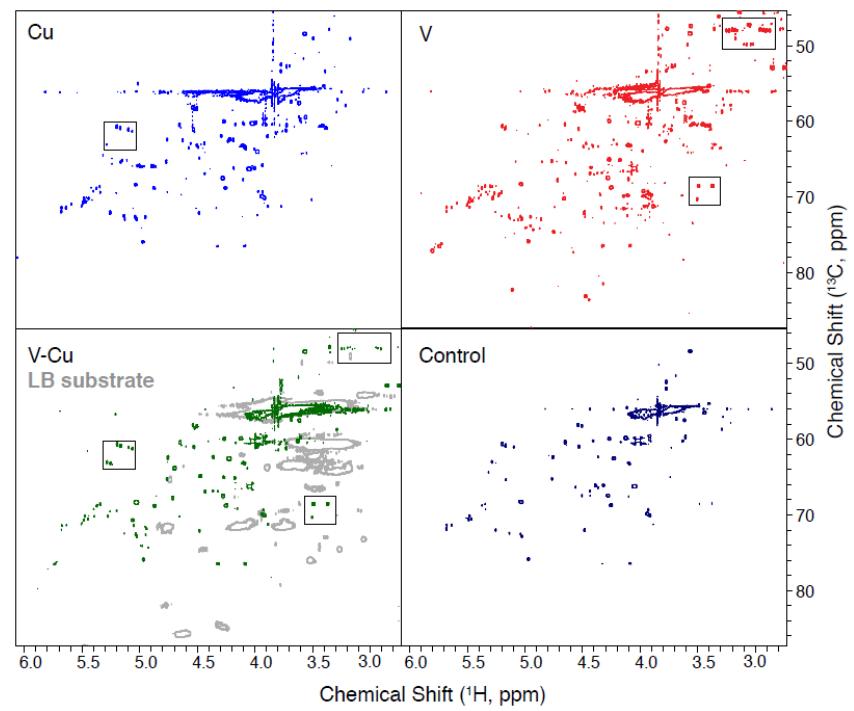

Fig. 7 Comparison of ${ }^{1} \mathrm{H}-{ }^{13} \mathrm{C}$ HSQC NMR spectra of the LB substrate and the bio-oils obtained upon $\mathrm{Cu}(\mathrm{OAc})_{2}$ catalysis, $\mathrm{VO}(\mathrm{acac})_{2}$ catalysis and $\mathrm{VO}(\mathrm{acac})_{2}-\mathrm{Cu}(\mathrm{OAc})_{2}$-catalysis in comparison to bio-oil obtained in the control process. Reaction conditions: $150{ }^{\circ} \mathrm{C}$, $10 \mathrm{~min}, 5$ bar initial $\mathrm{O}_{2}, 60 \mathrm{~mL}$ of $25 \mathrm{~g} / \mathrm{L}$ lignin in $2 \mathrm{M} \mathrm{NaOH}$. Amounts and ratios of respective catalysts are given in Table S1, ESIt and an enlarged version of Fig. 7 can be found in Fig. S4, ESIt.
The NMR spectra of the bio-oils obtained upon V-Cu catalysis (green), $\mathrm{Cu}(\mathrm{OAc})_{2}$ catalysis (blue), $\mathrm{VO}(\mathrm{acac})_{2}$ catalysis (red) and control reaction (dark blue), as well as the substrate (gray) are compared in Fig. 7. Most of the linkages detected in the substrate disappeared in both the catalyzed and the control samples, suggesting cleavage of those bonds as well as the efficient separation of monomers from higher oligomers during the workup procedure. Moreover, different structural motifs were formed in the spectra of the $\mathrm{Cu}(\mathrm{OAc})_{2^{-}}$and $\mathrm{VO}(\mathrm{acac})_{2}$-catalyzed reactions, as highlighted by the black boxes in Fig. 7 . The signals for the motifs were situated within the oxygenated aliphatic region for the Cu-catalyzed bio-oil. For the bio-oil obtained by the V-catalyst, signals were detected that did not emerge in control reactions or for the Cu-catalyzed reactions. The spectrum of the reaction employing combined $\mathrm{V}-\mathrm{Cu}$ catalysis contained signals for characteristic structural motifs of individual spectra for both catalysts, suggesting a combined effect. The observation that different reactivity patterns can be obtained by $\mathrm{V}$-Cu catalysis compared to their monometallic analogues indicates the potential of the catalytic system for the oxidative cleavage of complex lignin macromolecules, supporting previous studies on lignin model compounds. ${ }^{47}$ However, detailed insights into the combined effect and probable $\mathrm{V}-\mathrm{Cu}$ interactions will require a dedicated mechanistic study. A favorable effect of $\mathrm{V}$ $\mathrm{Cu}$ interactions towards oxidation was suggested not only by the emergence of characteristic structural motifs in the linkage region but also by a higher amount of $\mathrm{HCO}_{3}{ }^{-}$produced upon $\mathrm{V}$ $\mathrm{Cu}$ catalysis relative to formic acid if compared to the other tested catalysts (Fig. S3, ESI + ). A complimentary method that provides insight into the oxidative formation of other compounds with few $\mathrm{CH}$ groups was used in UHPLC-HRMS analysis of corresponding post-reaction materials.

\section{UHPLC-HRMS analysis}

Ultra-high pressure reversed-phase liquid chromatography was performed on the LB substrate, the product from the control experiment and on the organic (bio-oil) and aqueous fractions obtained upon $\mathrm{V}-\mathrm{Cu}$ catalysis. After data reduction and filtering, 168 different organic molecules could be identified. The chemical similarity between different streams was firstly elucidated using hierarchical cluster analysis (Fig. 8). The prevalence of the particular molecule between the samples is denoted by the blue color (the more intense the color, the higher is the relative concentration of the particular species). The differentiation of the clusters is depicted with the corresponding dendrograms. 


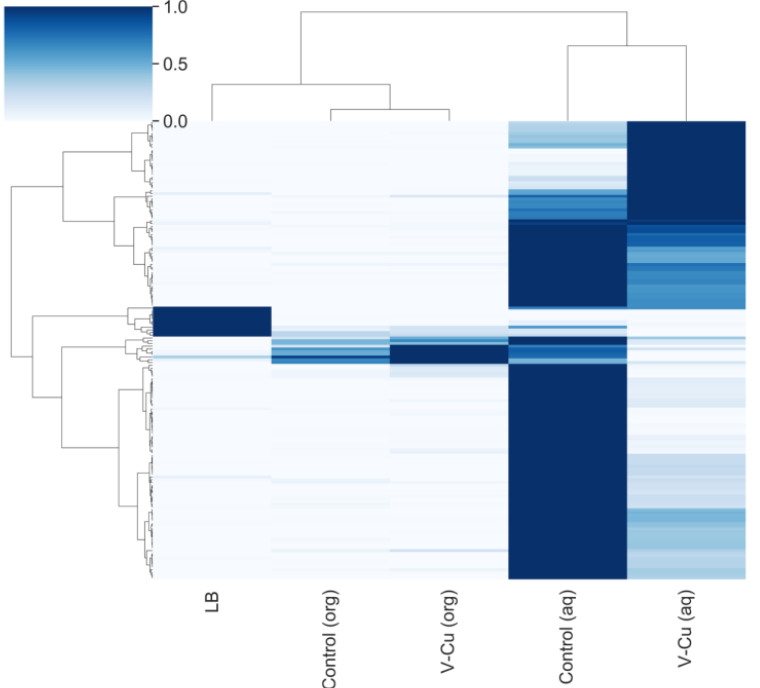

Fig. 8 Hierarchical cluster analysis of organic and aqueous LB as well as samples from control and V-Cu catalyzed reactions using Ward's method and Euclidean metric.

The clustering analysis revealed a clear separation of the aqueous samples from LB and organic samples (vertical separation). Separation, according to the chemical species (horizontal separation), showed that the vast majority of the organic species present in the feed were successfully converted during the process, which is in agreement with the observations from NMR spectroscopy and demonstrated by high bio-oil yields. The control and $\mathrm{V}-\mathrm{Cu}$ catalyzed organic samples had a similar composition, but the V-Cu catalyzed sample showed a focus that was more pronounced on fewer, selected species (see Figs. 9 and 10). The same focusing trend was also evident in the aqueous samples. In essence, the control samples comply with the majority of the detected species, whereas the V-Cu sample showed district clustering, which is further characterized below.

\section{UHPLC-HRMS characterization of the products in aqueous phase}

The volcano plot (common negative logarithm of the $p$-value versus the binary logarithm of the ratio between two samples) of the HRMS data for the aqueous phases resulting from $\mathrm{V}-\mathrm{Cu}$ and control samples is shown in Fig. 9. Providing a rigorous statistical analysis, the volcano plot is dividing the chemical species into significantly upregulated (significantly present in $\mathrm{V}-\mathrm{Cu}$ ), significantly downregulated (significantly present in control samples), and non-affected (statistically non-separable between samples) species. In total, 161 chemical species passed the cutoff criteria and were classified into 14 mainly present in the V-Cu catalyzed, 56 mostly present in the control sample and 91 species that were statistically indistinguishable between the samples.

The chemical nature of those groups was assessed by van Krevelen and 2D-kernel density analysis ${ }^{48}$ (Fig. S5, ESI + ). The aqueous control sample was characterized by a maximum in molecular weight around $200 \mathrm{Da}$ with a prominent shoulder around $110 \mathrm{Da}$, simultaneously having a double peak of double bond equivalents (DBE) around 2.5 and 6.5.

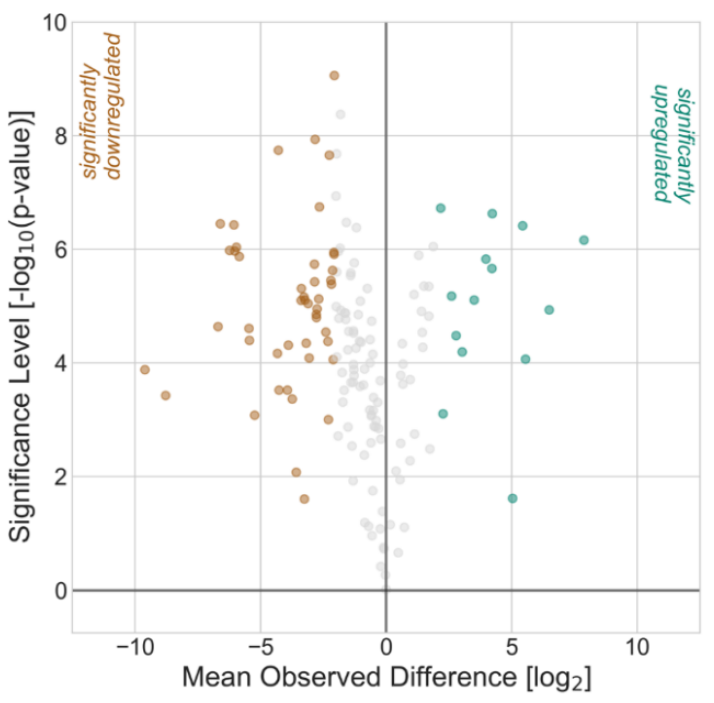

Fig. 9 Volcano plot of V-Cu catalyzed vs control aqueous sample.

The van Krevelen plot showed clustering around $1 \mathrm{H} / \mathrm{C}$ and $0.6 \mathrm{O} / \mathrm{C}$ ratios, indicating the presence of oxygenated and aromatic species. The non-affected species had a wide distribution, ranging from 0.5-2.0 H/C and 0.5-1.25 O/C. The MWD showed Gaussian distribution near 120 Da and a DBE of 1.8 , with a shoulder reaching to higher DBE values. In contrast, the $\mathrm{V}$-Cu catalyzed aqueous sample had a sharp peak at a DBE of 2 and a MWD plateau between 120 and $180 \mathrm{Da}$. The van Krevelen Plot revealed aliphatic oxygenated species clustering around $1.6 \mathrm{H} / \mathrm{C}$ and $0.8 \mathrm{O} / \mathrm{C}$.

\section{UHPLC-HRMS characterization of the products in organic phase}

The volcano plots of control vs. LB, V-Cu vs. LB, and V-Cu vs. control samples are shown in Figs. S6 and S7, ESIt and Fig. 10, respectively. As observed in the cluster analysis (Fig. 8), most of the species present in LB had been converted. With the help of volcano plots, the detailed characterization of those changes could be described. The control experiment yielded 12 out of 37 molecular species into 9 new species, leaving 16 species as statistically indistinguishable. The V-Cu catalyzed reaction was able to produce 13 new species, reducing the number of indistinguishable species from 16 to 12 . Those species could either result from different depolymerization pathways, or conversion from already depolymerized oligo- or monomers. A combination of both presenting strategies is also possible.

The volcano plot of $\mathrm{V}-\mathrm{Cu}$ catalyzed vs. control reaction (Fig. 10) emphasizes that three chemical species surpassed the criteria being statistically indistinguishable between control and V-Cu sample. These species may be primarily produced by temperature- and $\mathrm{pH}$-induced conversion of LB and may only be affected by the catalyst to a minor extent. The chemical nature of the statistically indistinguishable species was characterized using van Krevelen analysis (Fig. S8, ESIt). The characteristic of these species is given by $\mathrm{H} / \mathrm{C}$ ratio of 1 and $\mathrm{O} / \mathrm{C}$ ratio ranging from $0.25-0.7$, thus representing typical oxygenated aromatic species. These species are monomeric as could be deduced from MWD plots, with a maximum in MWD 
at about $160 \mathrm{Da}$ (Fig. S9, ESIt). Vanillin and vanillic acid were clearly upregulated, albeit with $\log _{2}$-values at 1.4 and 1.8 for vanillin and vanillic acid, respectively, thus not matching the criteria to be significantly upregulated.

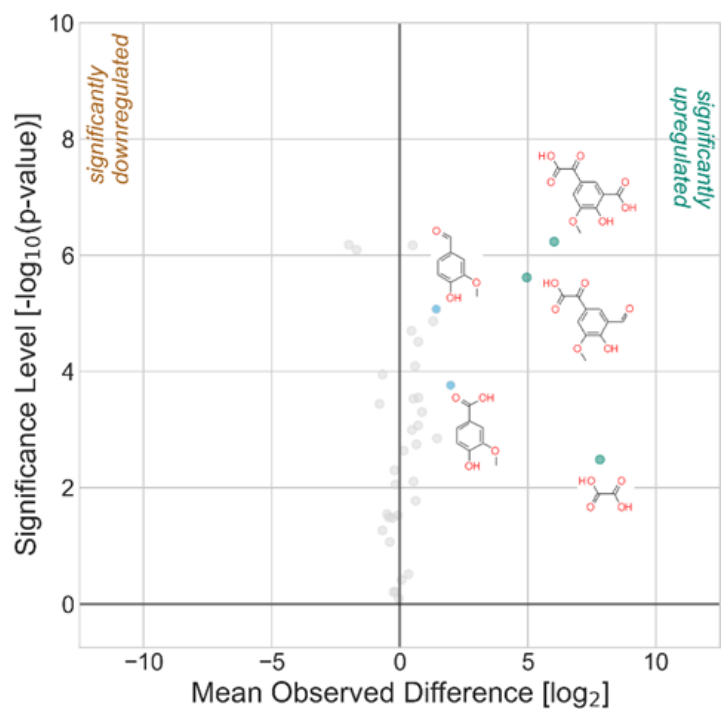

Fig. 10 Volcano plot of V-Cu catalyzed vs. control organic sample. Significantly upregulated species and corresponding tentative structures are shown with a green dot. Vanillin and vanillic acid are shown with a light-blue dot for comparison. Note that the two aromatic species possessing an oxoacetic functionality are tentative structures.

The selectivity of the employed $\mathrm{V}-\mathrm{Cu}$ catalyst is demonstrated by the chemical nature of the upregulated species (chemical structures depicted with green dots in Fig. 10 , confirmed structure of oxalic acid and tentative structures for aromatic molecules). These species exceeded a 30 -fold increase in the V-Cu catalyzed sample. Although the structures of the upregulated species are tentative, the presence of the oxoacetic group in their structure is certain. All structures present in the ChemSpider database having the proposed formula, and which collision-induced fragment structure could be explained using the FiSH scoring algorithm, have an oxoacetic group (Fig. S10, ESI + ). Similar to vanillin and vanillic acid, oxalic acid was identified independently, using authentic standards.

The ability of the V-Cu catalyst to prevent further degradation of the oxoacetic group thus potentially opens a specific route towards the production of platform-relevant aromatic species with an oxoacetic functional group.

\section{Optimization of reaction parameters}

The initial screening identified $\mathrm{VO}(\mathrm{acac})_{2}-\mathrm{Cu}(\mathrm{OAc})_{2}$ as the most promising of the investigated catalyst systems. The performance of the system was further optimized in order to enhance the yield in vanillin and vanillic acid and to contribute to a deeper understanding of the catalytic system itself. Several parameters concerning the reaction conditions and the composition of the $\mathrm{V}-\mathrm{Cu}$ catalyst were accordingly investigated, including oxygen pressure, temperature, reaction time, $\mathrm{V}: \mathrm{Cu}$ ratio and catalyst-to-lignin ratio (Fig. 11).

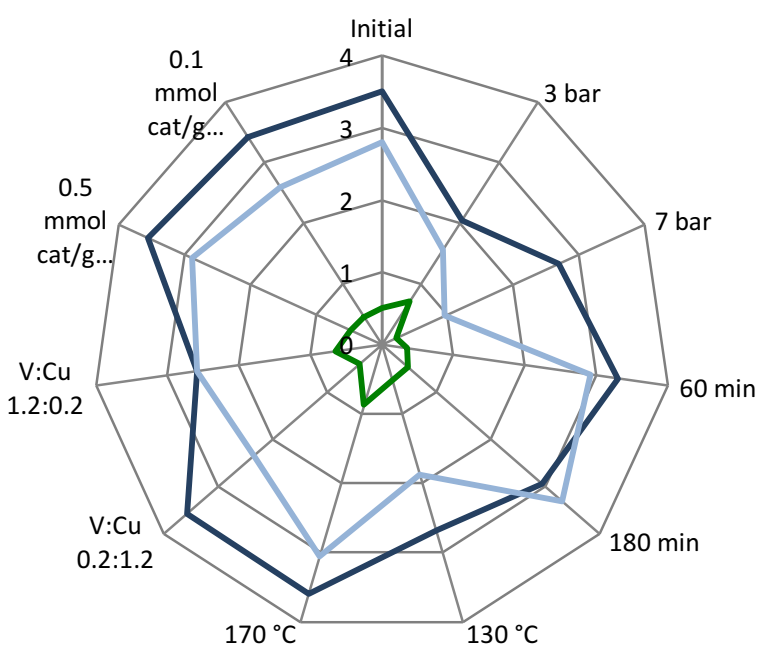

$\longrightarrow$ Vanillin [\%] $\quad$ Vanillic acid [\%] —Acetovanillone [\%]

Fig. 11 Yields obtained for vanillin, vanillic acid and acetovanillone at different reaction conditions. Variations from initial reaction conditions are indicated. Initial reaction conditions: $150{ }^{\circ} \mathrm{C}, 10 \mathrm{~min}, 5$ bar initial $\mathrm{O}_{2}, 60 \mathrm{~mL}$ of $25 \mathrm{~g} / \mathrm{L}$ lignin in $2 \mathrm{M} \mathrm{NaOH}, 1.4$ $\mathrm{mmol} \mathrm{VO}(\mathrm{acac})_{2}-\mathrm{Cu}(\mathrm{OAc})_{2}(\mathrm{~V}: \mathrm{Cu}$ ratio $=0.75)$.

In terms of initial oxygen partial pressure, neither a decrease of the pressure to 3 bar nor an increase to 7 bar yielded higher amounts of vanillin or vanillic acid compared to reactions conducted in the presence of 5 bar $\mathrm{O}_{2}$ partial pressure. However, a trend could be observed regarding amounts of acetovanillone, which showed higher yields at lower oxygen partial pressure). In contrast, the yield in bio-oil was found to be highly dependent on partial pressure, obtaining higher yields with increasing pressure ranging from $34 \%$ (3 bar) to $56 \%$ ( 7 bar), as shown in Table S2, ESIt.

Upon increasing the reaction time from $10 \mathrm{~min}$ to $60 \mathrm{~min}$ and $180 \mathrm{~min}$, a trend towards the production of more vanillic acid and less vanillin was observed. Changes in vanillin and vanillic acid showed opposite trends, with vanillin yields decreasing from $3.5 \%$ (10 $\mathrm{min}$ ) to $3.3 \%$ (60 $\mathrm{min}$ ) and $2.9 \%$ (180 $\mathrm{min})$, while yields of vanillic acid increased from $2.8 \%$ (10 $\mathrm{min}$ ) to $2.9 \%$ (60 $\mathrm{min}$ ) and $3.3 \%$ (180 $\mathrm{min})$. This observation is thus consistent with the oxidation of vanillin to vanillic acid over time. ${ }^{44}$ Bio-oil formation was clearly favored by increasing the reaction times, with yields up to $60 \%$ (both 60 and $180 \mathrm{~min}$ ) compared to $48 \%$ (10 $\mathrm{min})$. SEC analysis of the reaction mixtures at different reaction times resulted in similar MWDs, as displayed in Fig. S11, ESIt. Again, values for $\mathrm{M}_{\mathrm{w}}$ and $M_{n}$ were slightly lower than for the control reaction, while the obtained absorbance signal was significantly higher for the catalyzed samples.

Decreasing the reaction temperature from 150 to $130{ }^{\circ} \mathrm{C}$ resulted in a considerable decrease in yields of both vanillin and vanillic acid. Such observations are consistent with previous results, ${ }^{19}$ where a drop in the yields of vanillin and vanillic acid was reported upon changing the reaction 
temperature from 150 to $125^{\circ} \mathrm{C}$. Oppositely, a higher reaction temperature from 150 to $170{ }^{\circ} \mathrm{C}$ provided an increase in the obtained yield of vanillin from 3.5 to $3.6 \%$ and of vanillic acid from 2.8 to $3.1 \%$, respectively. Although the yield increased, the effect was not as pronounced, which is in line with recent reports on the oxidation of native lignin. ${ }^{19}$ Noticeably, the yield in acetovanillone was not affected by lowering the temperature, while an increase to $170{ }^{\circ} \mathrm{C}$ increased the yield from $0.5 \%$ ( 130 and $150{ }^{\circ} \mathrm{C}$ ) to $0.9 \%$. However, due to the rather long heating time of the autoclave (ca. $45 \mathrm{~min}$ to 150 ${ }^{\circ} \mathrm{C}$ ), it remained difficult to distinguish the effects of reaction temperature and of reaction time.

Altering the ratio of $\mathrm{VO}(\mathrm{acac})_{2}$ and $\mathrm{Cu}(\mathrm{OAc})_{2}$ (i.e. $\mathrm{V}: \mathrm{Cu}$ molar ratio) in the reaction, while maintaining the metal-tolignin ratio, yielded results that support a possible synergistic effect of $\mathrm{VO}(\mathrm{acac})_{2}$ and $\mathrm{Cu}(\mathrm{OAc})_{2}$, as the highest yields of vanillin and vanillic acid were found in the presence of comparable amounts of both catalysts. An increase in the fraction of $\mathrm{Cu}(\mathrm{OAc})_{2}$ led to a decrease in the yield of vanillic acid, whereas the amount of produced vanillin remained rather constant when decreasing the $\mathrm{V}: \mathrm{Cu}$ ratio relative to standard conditions with $\mathrm{V}: \mathrm{Cu}=0.75$ (0.6:0.8 molar ratio). On the other hand, increasing the $\mathrm{V}: \mathrm{Cu}$ ratio both decreased the yield of vanillin and vanillic acid, while the yield of acetovanillone was slightly increased.

\section{Influence of catalyst amount and catalyst reuse}

To address the technical viability of the reaction system, the catalyst-to-lignin ratio was further investigated. As the initial amount of catalyst to lignin was rather high compared to previously reported studies, ${ }^{19,33}$ only lower amounts of catalyst-to-lignin were considered. No major changes in the amount of produced vanillin and vanillic acid could be observed when reducing the amount of catalyst from $0.9 \mathrm{mmol} / \mathrm{g}$ lignin ( $1.4 \mathrm{mmol} \mathrm{V}-\mathrm{Cu}$ ) to $0.5 \mathrm{mmol} / \mathrm{g}$ lignin. When employing $0.1 \mathrm{mmol}$ catalyst/g lignin, the yield in vanillin and vanillic acid decreased slightly, but only by approximately 0.2 $0.3 \%$. These data suggest that, in order to improve the viability of a possible industrial implementation, a lower amount of catalyst may be utilized without a drastic reduction in vanillin/vanillic acid yield. Ideal conditions for implementation in production thus remain to be established.

After the depolymerization reaction, the V-Cu catalyst was separated by EtOAc extraction into an aqueous phase containing $\mathrm{NaCl}$ that originates from the LB substrate and the $\mathrm{HCl}$ acidification step (Fig. 2). Thus, a preliminary experiment was performed to assess the sensitivity of the catalyst to recycling in the presence of increasing concentrations of $\mathrm{NaCl}$, when recycling was carried out according to the procedure proposed in Fig. S12, ESIt. Unfortunately, the recycled catalyst showed rather poor activity, with a yield in vanillin that was even lower than in the control experiment (1.9 compared to $3.0 \%$, respectively). Apart from the yield in vanillic acid, which was slightly higher, all the other quantified aromatic compounds yielded comparable amounts as in the control reactions. Problems within the proposed recycling procedure may result from the increasing concentrations of $\mathrm{NaCl}$ as a consequence of acidification and subsequent basification. This problem might be addressed by using an alternative acid than $\mathrm{HCl}$ that forms less problematic salts, or by separation of the formed salts, e.g. through ion exchange or membrane filtration. Another significant aspect is the impact of the recycling procedure on the catalyst. The harsh changes in $\mathrm{pH}$ possibly change the chemical composition of the catalyst, in this way affecting its activity towards vanillin and vanillic acid, as suggested by these initial results. Characterization of the recycled catalyst and a comparison to the fresh catalyst might give insight into reasons for the lower catalytic activity. Overall, the challenges in recyclability represent a possible starting point for future research and should be considered for potential future adaptations in the design of catalytic system.

\section{Conclusions}

The ability to catalyze the oxidative depolymerization of technical lignin with different homogeneous transition-metal catalysts was examined, with $\mathrm{VO}(\mathrm{acac})_{2}-\mathrm{Cu}(\mathrm{OAc})_{2}$ showing the most promising results. The obtained aromatic monomers included vanillin, vanillic acid and acetovanillone, and effective depolymerization to low molecular weight compounds was confirmed by SEC-UV. Optimization of the reaction parameters indicated 5 bar initial oxygen pressure and a molar V:Cu ratio of 0.75 to be optimal, whereas higher temperature and reaction time only had a minor influence on the monomer yield. However, with increasing oxygen partial pressure and reaction time, bio-oil yields increased up to $60 \%$.

A combined effect of $\mathrm{VO}(\mathrm{acac})_{2}$ and $\mathrm{Cu}(\mathrm{OAc})_{2}$ on the product yield was observed as characteristic products of both catalysts were identified in reaction mixtures upon combined $\mathrm{V}-\mathrm{Cu}$ catalysis. The statistical analysis illustrated a focusing effect of the examined catalyst towards selected products, highlighting a more than 30 -fold increase in three molecules possessing an oxoacetic group. This increase may open new routes towards platform chemicals with oxoacetic functionalities. Catalyst recycling indicated that implementation under industrially viable conditions remains a subject for future research. Such implementation bears promise, as the findings of this study underline the opportunity of sustainably producing high-value aromatic chemicals from industrial lignin streams.

\section{Conflicts of interest}

There are no conflicts to declare.

\section{Acknowledgements}

This research project was supported by the Technical University of Denmark, Lund University, the Swedish Foundation for Strategic Research (RBP14-0052), the Södra Research Foundation (2019-149), the Swedish Energy Agency (45241-1 and 49701-1), and the Swiss Innovation Agency 
Innosuisse in the framework of the Swiss Competence Center for Energy Research (SCCER BIOSWEET). We thank Henrik Almqvist for technical support with SEC. The 2D NMR spectra were recorded using the $800 \mathrm{MHz}$ spectrometer at the NMR Center DTU, supported by the Villum Foundation. Part of this work was supported by and performed within the Energy System Integration platform at the Paul Scherrer Institute.

\section{References}

1 Z. Sun, B. Fridrich, A. De Santi, S. Elangovan and K. Barta, Chem. Rev., 2018, 118, 614-678.

2 S. Gillet, M. Aguedo, L. Petitjean, A. R. C. Morais, A. M. da Costa Lopes, R. M. Lukasik and P. T. Anastas, Green Chem., 2017, 19, 4200-4233.

3 P. Zhu, O. Y. Abdelaziz, C. P. Hulteberg and A. Riisager, Curr. Opin. Green Sustain. Chem., 2020, 21, 16-21. J. Zakzeski, P. C. A. Bruijnincx, A. L. Jongerius and B. M. Weckhuysen, Chem. Rev., 2010, 110, 3552-3599. G. De Gonzalo, D. I. Colpa, M. H. M. Habib and M. W. Fraaije, J. Biotechnol., 2016, 236, 110-119. V. K. Ponnusamy, D. D. Nguyen, J. Dharmaraja, S. Shobana, J. R. Banu, R. G. Saratale, S. W. Chang and G. Kumar, Bioresour. Technol., 2019, 271, 462-472. A. J. Ragauskas, G. T. Beckham, M. J. Biddy, R. Chandra, F. Chen, M. F. Davis, B. H. Davison, R. A. Dixon, P. Gilna, M. Keller, P. Langan, A. K. Naskar, J. N. Saddler, T. J. Tschaplinski, G. A. Tuskan and C. E. Wyman, Science, 2014, 344, 1246843 1-10. F. G. Calvo-Flores, J. A. Dobado, J. Isac-García and F. J. Martín-Martínez, Lignin and Lignans as Renewable Raw Materials: Chemistry, Technology and Applications, 2015. C. Mattsson, S. Andersson, T. Belkheiri, L. Åmand, L. Olausson, L. Vamling and $\mathrm{H}$. Theliander, Biomass and Bioenergy, 2016, 95, 364-377. G. L. F. Gellerstedt and E. G. Henriksson, in Monomers, Polymers and Composites from Renewable Resources, 2008, pp. 201-224.

11 P. Azadi, O. R. Inderwildi, R. Farnood and D. A. King, Renew. Sustain. Energy Rev., 2013, 21, 506-523.

12 H. Lange, S. Decina and C. Crestini, Eur. Polym. J., 2013, 49, 1151-1173.

13 J. C. Biermann, Handbook of pulping and papermaking: Second Edition, 1996.

14 J. C. Carvajal, Á. Gómez and C. A. Cardona, Bioresour. Technol., 2016, 214, 468-476.

15 C. G. Boeriu, D. Bravo, R. J. A. Gosselink and J. E. G. Van Dam, Ind. Crops Prod., 2004, 20, 205-218.

16 L. Shuai and B. Saha, Green Chem., 2017, 19, 3752-3758.

17 S. Guadix and M. Meenakshisundaram, Top. Catal., 2018, 61, 183-198.

18 J. J. Bozell, Top Curr Chem, 2014, 353, 229-256.

19 W. Schutyser, J. S. Kruger, A. M. Robinson, R. Katahira, D. G. Brandner, N. S. Cleveland, A. Mittal, D. J. Peterson, R. Meilan, Y. Román-Leshkov and G. T. Beckham, Green Chem., 2018, 20, 3828-3844. and C. P. Hulteberg, ACS Sustain. Chem. Eng., 2019, 7, 11640-11652.
21 R. Ma, M. Guo and X. Zhang, Catal. Today, 2018, 302, 5060. T. Vangeel, W. Schutyser, T. Renders and B. F. Sels, Top Curr Chem, 2018, 376, 1-18.

R. Behling, S. Valange and G. Chatel, Green Chem., 2016, 18, 1839-1854.

N. Abad-Fernández, E. Pérez and M. J. Cocero, Green Chem., 2019, 21, 1351-1360.

E. Pérez and C. O. Tuck, Eur. Polym. J., 2018, 99, 38-48. O. Y. Abdelaziz, S. Meier, J. Prothmann, C. Turner, A. Riisager and C. P. Hulteberg, Top. Catal., 2019, 62, 639648.

H. Wang, M. Tucker and Y. Ji, J. Appl. Chem., 2013, 2013, 19.

S. Bjelić, L. Garbuio, K. R. Arturi, J. A. van Bokhoven and F. Vogel, ChemistrySelect, 2018, 3, 11680-11686.

P. J. Deuss and K. Barta, Coord. Chem. Rev., 2016, 306, 510-532.

T. Rinesch, J. Mottweiler, M. Puche, A. Corma and C. Bolm, ACS Sustain. Chem. Eng., 2017, 5, 9818-9825.

J. Mottweiler, M. Puche, C. Räuber, T. Schmidt, P.

Concepción, A. Corma and C. Bolm, ChemSusChem, 2015, 8, 2106-2113.

E. B. Clatworthy, J. L. Picone-Murray, A. K. L. Yuen, R. T. Maschmeyer, A. F. Masters and T. Maschmeyer, Catal. Sci. Technol., 2019, 9, 384-397.

Y. Ma, Z. Du, J. Liu, F. Xia and J. Xu, Green Chem., 2015, 17, 4968-4973.

B. Sedai and R. Tom Baker, Adv. Synth. Catal., 2014, 356, 3563-3574.

S. K. Hanson, R. Wu and L. A. P. Silks, Angew. Chemie - Int. Ed., 2012, 124, 3410-3413.

Y. Ma, Z. Du, F. Xia, J. Ma, J. Gao and J. Xu, RSC Adv., 2016, 6, 110229-110234.

S. K. Hanson, R. T. Baker, J. C. Gordon, B. L. Scott and D. L. Thorn, Inorg. Chem., 2010, 49, 5611-5618.

W. Schutyser, T. Renders, S. Van Den Bosch, S. F. Koelewijn, G. T. Beckham and B. F. Sels, Chem. Soc. Rev., 2018, 47, 852-908.

O. Y. Abdelaziz, A. A. Al-Rabiah, M. M. El-Halwagi and C. P. Hulteberg, ACS Sustain. Chem. Eng., 2020, 8, 8823-8829. P. Tomani, Cellul. Chem. Technol., 2010, 44, 53-58. I. A. Lewis, S. C. Schommer, B. Hodis, K. A. Robb, M. Tonelli, W. M. Westler, M. R. Sussman and J. L. Markley, Anal. Chem., 2007, 79, 9385-9390.

K. R. Arturi, S. Kucheryavskiy, R. P. Nielsen, M. Maschietti, F. Vogel, S. Bjelić and E. G. Søgaard, J. Supercrit. Fluids, 2019, 143, 211-222.

W. Jia, Y. Li, A. Du, Z. Fan, R. Zhang, L. Shi, C. Luo, K. Feng, J. Chang and X. Chu, Food Chem., 2020, 315, 126308.

E. A. B. da Silva, M. Zabkova, J. D. Araújo, C. A. Cateto, M. F. Barreiro, M. N. Belgacem and A. E. Rodrigues, Chem. Eng. Res. Des., 2009, 87, 1276-1292.

L. Yang, K. Seshan and Y. Li, Catal. Today, 2017, 298, 276297. 
Y. Mathieu, J. D. Vidal, L. Arribas, N. Abad, S. Iborra and A. Corma, ChemSusChem, , DOI:10.1002/cssc.202001295.

47 B. Sedai, C. Díaz-Urrutia, R. T. Baker, R. Wu, L. A. P. Silks and S. K. Hanson, ACS Catal., 2011, 1, 794-804.

48 S. Bjelić, J. Yu, B. B. Iversen, M. Glasius and P. Biller, Energy Fuels, 2018, 32, 3579-3587. 